\title{
CARACTERIZAÇÃO DO PERFIL DOS CONSUMIDORES DE PEIXE NO MUNIĆIPIO DE BELÉM, ESTADO DO PARÁ, BRASIL
}

\author{
Flávio Paixão Mangas* \\ Fabrício Khoury Rebello** \\ Marcos Antônio Souza dos Santos*** \\ Cyntia Meireles Martins ${ }^{* * * *}$
}

RESUMO: O artigo analisa o perfil dos consumidores de peixe no município de Belém, Estado do Pará, Brasil. Os dados foram obtidos a partir de um formulário de pesquisa disponibilizado pela ferramenta Google Docs junto a uma rede de contatos constituída por servidores públicos federais, estaduais e municipais, professores, bancários, autônomos e comerciantes com diversos graus de formação e renda. Foram validados 400 questionários. A margem de erro adotada foi de 5\%, com intervalo de confiança de $95 \%$. Os resultados demonstram que $88 \%$ dos entrevistados consideram o preço do peixe alto. O supermercado foi o local com maior preferência para compra do produto $(51,75 \%$ dos consumidores). Com relação à verificação do frescor do peixe, $80,25 \%$ responderam que sabem realizar tal procedimento. Os consumidores com formação de nível médio e superior revelaram que o acesso a informações sobre a origem do peixe, qualidade e validade do produto favorecem suas decisões de compra. Em geral, o consumidor belenense aprecia bastante a carne de peixe, consumindo, em média, $21,96 \mathrm{~kg} / \mathrm{hab}$./ano, principalmente em função de fatores culturais e pela abundância do produto na região. Ficou evidenciada uma mudança no perfil do consumidor de peixe na capital paraense que, ao longo dos anos, se tornou mais crítico e exigente com relação à qualidade do produto ofertado e quanto ao local de preferência para realizar suas compras que, agora, passou a ser o supermercado em detrimento da feira livre.

PALAVRAS-CHAVE: Amazônia; Consumidor; Mercado; Pescado.

\footnotetext{
Engenheiro de Pesca; Universidade Federal Rural da Amazônia (UFRA), Brasil.

** Doutor em Ciências Agrárias; Docente da Universidade Federal Rural da Amazônia (UFRA), no Instituto Socioambiental e dos Recursos Hídricos (ISARH); Pesquisador do Grupo Cadeias Produtivas, Mercados e Desenvolvimento Sustentável, Amazônia, Brasil. E-mail: fabriciorebello@hotmail.com

${ }^{* * *}$ Mestre em Economia pela Universidade da Amazônia (UNAMA); Pró-Reitor Adjunto de Planejamento e Desenvolvimento Institucional da Universidade Federal Rural da Amazônia (UFRA), Amazônia, Brasil.

**** Doutora em Ciências Agrárias; Docente da Universidade Federal Rural da Amazônia (UFRA) e Docente permanente do Programa de Pós-graduação em Administração - PPAD (Mestrado/Doutorado); Pesquisadora do Grupo Cadeias Produtivas, Mercados e Desenvolvimento Sustentável, Amazônia, Brasil.
} 


\title{
THE PROFILE OF FISH CONSUMERS IN BELÉM, BRAZIL
}

\begin{abstract}
The profile of fish consumers in the municipality of Belém PA Brazil is analyzed from data retrieved from the Google Docs research form filled by federal, state and municipal civil servants, teachers, bank employees, freelance and traders, with different schooling and income. Four hundred questionnaires were received and the error margin adopted lay at 5\% with a 95\% confidence interval. Results revealed that $88 \%$ of people interviewed considered the price of fish high. The supermarket was the place of preference (51.75\% of consumers) for buying the product. Moreover, $80.25 \%$ answered that they verify the freshness of the fish for sale. Consumers with high school or higher levels stated that access of information on the origin of fish, its quality and expiring date weigh in the purchasing decision. As a rule, Belém consumers highly appreciate fish, averaging a consumption of 21.96 $\mathrm{kg} /$ inhab./year, mainly due to cultural factors and the abundance of the product in the region. Changes in consumers' profile occurred since they became more critical and demanding with regard to quality; the place of preference for purchasing the product, or rather, the supermarket is preferred to the open-air fair.
\end{abstract}

KEY WORDS: Amazon; Consumer; Market; Fish.

\section{INTRODUÇÃO}

O peixe é uma fonte de proteína de baixo valor calórico, rico em ácidos graxos poli-insaturados da família omêga-3. A divulgação de estudos que associam o seu consumo à redução do risco de doenças cardiovasculares e de alguns tipos de câncer, bem como no tratamento de doenças inflamatórias como a artrite reumatoide, tem causado, nos últimos anos, um aumento na sua demanda (BRASIL, 2006).

O Brasil dispõe de condições naturais muito favoráveis à produção de pescados, pois apresenta uma extensa faixa costeira e, aproximadamente, 13\% do total da reserva de água doce disponível no mundo (SIDONIO et al., 2012). Outros aspectos favoráveis são o clima propício para o crescimento de organismos cultivados e a diversidade de espécies existentes.

Entretanto, alguns fatores como a falta de investimentos no setor pesqueiro, manejo inadequado dos estoques, degradação das áreas de reprodução, hábito 
alimentar da população, preço elevado do produto, entre outros, contribuem para o baixo consumo de pescado no país.

Segundo a Organização das Nações Unidas para Agricultura e Alimentação (FAO, 2013), o consumo mundial de pescado foi de 116.960 mil toneladas em 2009, valor da ordem de $17 \mathrm{~kg} / \mathrm{hab}$./ano, ficando a frente dos outros tipos de carne como a bovina que apresentou um consumo mundial de 56.116 mil t, ou seja, cerca de $10 \mathrm{~kg}$ per capita. A carne suína, no mesmo ano, apresentou consumo mundial de 100.268 mil t (16 kg/hab./ano) e o consumo de aves foi da ordem de 71.860 mil t (10,5 $\mathrm{kg} /$ hab./ano). Ovinos e caprinos também são proteínas consumidas mundialmente, mas sua importância é menor se comparada às demais carnes citadas. $\mathrm{O}$ consumo das duas carnes foi de 13.139 mil t em 2009, o que representa $1,9 \mathrm{~kg}$ per capita consumidos no ano.

No Brasil, no mesmo período, o consumo per capita de pescado foi de 9,75 kg/hab./ano. Esse consumo médio deixa o país abaixo dos $12 \mathrm{~kg} / \mathrm{hab}$./ano recomendados pela Organização Mundial da Saúde (OMS).

A Região Norte é o grande destaque nacional no consumo de pescado, com ingestão per capita de 17,54 kg/hab./ano. O Estado do Amazonas é o maior consumidor per capita do país, com $30 \mathrm{~kg} / \mathrm{hab}$./ano e o Estado do Pará aparece com 18,69 kg/hab./ano (IBGE, 2013). Essa ênfase no consumo de pescado na região está associada a fatores culturais adquiridos dos povos indígenas, diversidade de espécies disponíveis e à variedade de receitas da gastronomia regional que tornam esse consumo maior que a média nacional.

Por outro lado, o controle da inflação proporcionado pela estabilização da economia, em 1994, assim como a ampliação do crédito, a elevação da renda e a expansão dos programas sociais de transferência de renda produziram no Brasil a criação de um mercado consumidor de massa, cada vez mais forte e complexo (VENTURA, 2010), que tende a influenciar o comportamento dos consumidores, entre os quais o de pescado.

Essa tendência de se consolidar um mercado consumidor mais exigente na escolha por produtos ou serviços força as empresas a adotarem novas estratégias de marketing. Conhecer o perfil de consumo que envolve quando, o que, por que, como, e principalmente, onde e de quem comprar é uma ferramenta muito utilizada 
pelos empresários visando construir novas estratégias para convencer o consumidor a adquirir seus produtos.

O objetivo deste estudo é caracterizar o perfil dos consumidores de peixe no município de Belém, capital do Estado do Pará, bem como identificar a preferência pelo local de compra e os fatores que determinam suas escolhas.

Assim, pretende-se contribuir com informações consistentes sobre 0 mercado consumidor desse importante produto da dieta alimentar dos paraenses, principalmente considerando que são poucos os trabalhos acadêmicos realizados no Estado do Pará sobre o tema proposto.

\section{MATERIAL E MÉTODOS}

O levantamento dos dados foi do tipo survey não supervisionado (não há um entrevistador presente). As pesquisas desse tipo se caracterizam pela interrogação das pessoas cujo comportamento se deseja conhecer. Basicamente, procede-se à solicitação de informações a um grupo significativo de pessoas acerca do problema estudado para, em seguida, mediante análise quantitativa, fazer-se inferências a partir dos dados coletados.

Foi elaborado um formulário contendo perguntas semiestruturadas visando obter dados sobre o perfil socioeconômico dos consumidores de peixe no município de Belém, bem como quanto ao local de compra preferido, aspectos do seu consumo e percepção da qualidade do peixe adquirido pelos consumidores.

O formulário foi disponibilizado pela ferramenta Google Docs, no período de 14 de dezembro de 2013 a 08 de janeiro de 2014, tendo sido apresentado na forma de link com uma mensagem introdutória explicando os propósitos da pesquisa e a forma de preenchimento do instrumento, assim como assegurando a não identificação individual de nenhuma resposta. $\mathrm{O}$ formulário foi enviado por e-mail a uma rede de contatos constituída por servidores públicos federais, estaduais e municipais, professores, bancários, autônomos e comerciantes com diversos graus de formação e renda. A determinação da amostra foi probabilística, procurandose diversificar o seu encaminhamento, visando atingir os vários estratos de renda, escolaridade e status social. 
O tamanho da amostra foi determinado a partir da equação 1, utilizada para o caso de populações infinitas, onde o tamanho do universo é superior a 100.000 habitantes. Esta fórmula é a mais adequada para o caso do município de Belém, cuja população estimada, em 2014, era de 1.432.844 habitantes (IBGE, 2015).

$$
n=\frac{\partial^{2} \cdot p \cdot q}{e^{2}}
$$

Onde: $\mathrm{n}=$ Tamanho da amostra;

$\partial^{2}=$ Nível de confiança escolhido, expresso em número de desvios-padrão;

$\mathrm{p}=$ Percentagem com a qual o fenômeno se verifica;

$q=$ Percentagem complementar (100-p);

$\mathrm{e}^{2}=$ Erro máximo permitido.

A margem de erro foi de 5\% com intervalo de confiança de $95 \%$ de probabilidade. Foram respondidos um total de 414 formulários, sendo que 14 foram descartados por problemas no preenchimento.

Os dados foram exportados para uma planilha eletrônica do Microsoft Excel $^{\odot}$ versão 2010. A partir do uso desse aplicativo, os dados foram analisados e, posteriormente, confeccionados gráficos e tabelas para apresentar os resultados da pesquisa.

\section{RESULTADO E DISCUSSÃO}

\subsection{PERFIL SOCIOECONÔMICO DOS CONSUMIDORES DE PEIXE NO MUNICÍPIO DE BELÉM}

Do total dos 400 questionários, verificou-se que 58,50\% dos respondentes eram do sexo masculino e $41,50 \%$ do feminino. A idade variou entre 19 e 63 anos, sendo que quase a metade (48,5\%) estava na faixa entre 31 e 40 anos, ou seja, pessoas em plena idade laboral, que muitas vezes optam por alimentos de mais fácil preparo, considerando o menor tempo despendido para afazeres domésticos. 
O estado civil com maior participação foi o dos casados (55,75\%), seguido pelos solteiros (32\%), divorciados (8\%), união estável e viúvo com 2,75\% e 1,50\%, respectivamente. Com relação à naturalidade, $89,25 \%$ são nascidos na capital do Estado, 8,25\% são oriundos de outros municípios paraenses e 2,50\% são de outras Unidades da Federação (UF).

Os dados revelam ainda que $67,75 \%$ possuem ou estão cursando o nível superior, seguidos pelos que possuem o ensino médio completo ou incompleto (31\%) e o ensino fundamental completo ou incompleto (1,25\%). Tal informação é importante, uma vez que permite correlacionar o grau de instrução do consumidor com o nível de informação disponível no processo de compra e consumo de bens e serviços, como será discutido mais adiante.

Com relação à renda familiar, verificaram-se percentuais muito próximos entre as faixas de 3 a 5 e 6 a 10 salários mínimos que, juntas, representam 69,50\% dos participantes. As faixas extremas (até um salário mínimo e acima de 20) participaram, respectivamente, com $1 \%$ e $4,25 \%$.

Quanto ao número de pessoas residindo por domicílio, constatou-se que $49,25 \%$ têm até três membros, sendo que 2,25\% moram sozinhos e 1,75\% possuem sete membros (número máximo informado). A média de indivíduos por domicílios foi da ordem de 3,54 .

\subsection{HÁBITOS DE CONSUMO DE PEIXE}

Quanto ao hábito alimentar, foi analisada a frequência de consumo de peixe, quantidade consumida, local de compra, fatores que influenciam a compra, formas de preparo do produto, tipo de corte consumido e o local de consumo.

As principais motivações apontadas para consumir o peixe foram o fato de ser considerado um alimento saudável (81,50\%) e gostarem do seu sabor $(81,25 \%)$. Com relação à frequência de consumo, observou-se que $44,75 \%$ consomem pescado de 1 a 2 vezes por semana (Gráfico 1), seguido por aqueles que consomem apenas duas vezes no mês $(26,50 \%)$. 


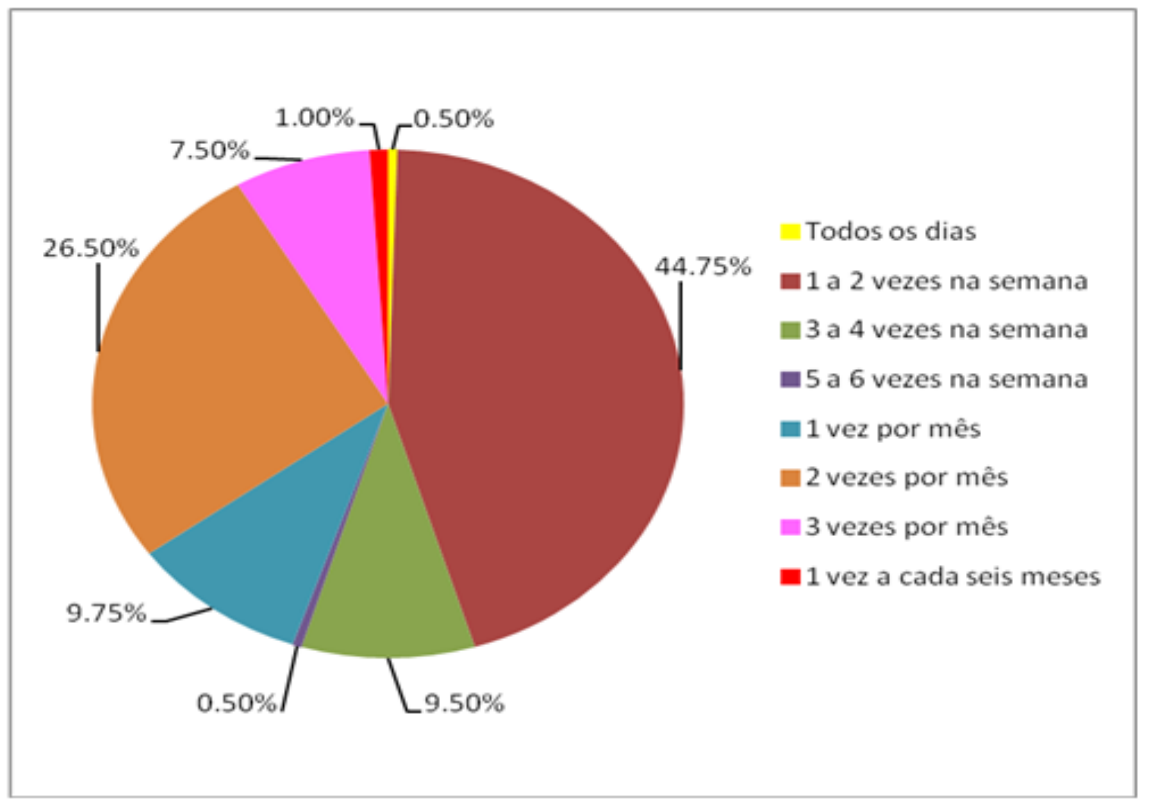

Gráfico 1. Frequência de consumo de peixe no município de Belém, jan. 2014 Fonte: Dados da pesquisa.

O consumo per capita mensal de peixe foi da ordem de $1,83 \mathrm{~kg}$, o que perfaz uma média anual de consumo de $21,96 \mathrm{~kg} / \mathrm{hab}$./ano, ou seja, quase o dobro (1,83 vezes) do consumo recomendado pela Organização Mundial da Saúde (OMS). A Tabela 1 apresenta o consumo mensal de peixe por domicílio (família), considerando várias faixas de ingestão do produto. Do total de informantes, $10,75 \%$ teriam dificuldade para atingir a recomendação de consumo da OMS. Na segunda faixa, as famílias médias (3,54 membros) com consumo de até $3,5 \mathrm{~kg} / \mathrm{mês}$ também não atingiriam esse patamar. As demais faixas, que representam 44,50\% dos entrevistados, possuem um consumo acima dessa indicação. As faixas de consumo mais representativas foram, respectivamente, entre 1,1 a 5,0 kg/mês (44,75\%) e 5,1 a $10,0 \mathrm{~kg} / \mathrm{mês}(25,75 \%)$. 
Tabela 1. Quantidade (kg) de peixe consumido mensalmente, segundo a frequência de consumo no município de Belém, Estado do Pará, jan. 2014

\begin{tabular}{ccc}
\hline Faixas de consumo mensal & Frequência (n) & Percentual (\%) \\
\hline $0,2 \mathrm{~kg}-1 \mathrm{~kg}$ & 43 & 10,75 \\
$1,1 \mathrm{~kg}-5 \mathrm{~kg}$ & 179 & 44,75 \\
$5,1 \mathrm{~kg}-10 \mathrm{~kg}$ & 103 & 25,75 \\
$10,1 \mathrm{~kg}-15 \mathrm{~kg}$ & 31 & 7,75 \\
$15,1 \mathrm{~kg}-20 \mathrm{~kg}$ & 32 & 8,00 \\
$20,1 \mathrm{~kg}-25 \mathrm{~kg}$ & 08 & 2,00 \\
$25,1 \mathrm{~kg}-28 \mathrm{~kg}$ & 04 & 1,00 \\
\hline
\end{tabular}

Fonte: Dados da pesquisa.

A Tabela 2 demonstra os principais locais de compra na preferência do consumidor belenense.

Tabela 2. Preferência do consumidor belenense (\%) quanto ao local de compra de peixe, jan. 2014

\begin{tabular}{cccccc}
\hline $\begin{array}{c}\text { Locais de } \\
\text { compra }\end{array}$ & Supermercado & $\begin{array}{c}\text { Peixaria } \\
\text { do bairro }\end{array}$ & $\begin{array}{c}\text { Mercado } \\
\text { municipal }\end{array}$ & Feira livre & $\begin{array}{c}\text { Produtor/ } \\
\text { Pescador }\end{array}$ \\
\hline Sempre & 20,75 & 2,50 & 5,25 & 12,25 & 3,25 \\
Frequentemente & 31,00 & 7,50 & 10,25 & 15,50 & 14,25 \\
Às vezes & 25,25 & 25,75 & 30,75 & 22,50 & 20,50 \\
Raramente & 14,50 & 20,50 & 27,00 & 21,50 & 26,75 \\
Nunca & 8,50 & 43,75 & 26,75 & 28,25 & 35,25 \\
\hline
\end{tabular}

Fonte: Dados da pesquisa.

O supermercado foi o canal de comercialização de maior preferência dos consumidores belenenses para compra do peixe $(51,75 \%)$. Este local possui a praticidade do pagamento a prazo ou débito em conta bancária, disponibilidade do produto, na maioria das vezes, independente de horário e maior tempo de prateleira em função da refrigeração. Na sequência da preferência aparece a feira 
livre $(27,75 \%)$, diretamente do produtor ou pescador $(17,50 \%)$, mercados $(15,50 \%)$ e na peixaria do bairro (10\%).

Algumas hipóteses podem ser levantadas quanto ao aspecto do consumidor não comprar o peixe em determinado canal. Neste quesito a peixaria se destacou com $43,75 \%$ de rejeição, provavelmente relacionado ao pequeno número de estabelecimentos no município, carência de conforto na infraestrutura disponibilizada pelas peixarias existentes e a falta de hábito do consumidor em frequentar esta modalidade de canal.

Produtor e pescador vêm em seguida com $35,25 \%$ das indicações, pelo fato da produção normalmente ser comercializada nas primeiras horas da manhã, em dias certos, em feiras do pescado ou portos específicos. A feira livre e o mercado municipal apresentam valores próximos, $28,25 \%$ e $26,75 \%$, respectivamente, devido aos problemas semelhantes encontrados em ambos como a pouca higiene na manipulação e conservação do peixe, segurança, falta de organização, entre outros. O supermercado teve o menor percentual de rejeição, com 8,50\% entre os entrevistados, uma vez que os consumidores percebem a comodidade, segurança, facilidade de pagamento, entre outros aspectos, proporcionados por esse canal de comercialização. Vale ressaltar que no supermercado a venda do peixe ocorre em todos os horários de funcionamento do estabelecimento, inclusive no horário noturno.

Tal resultado corrobora com o estudo de Silveira et al. (2012), realizado no município de Rio Grande (RS), onde o supermercado foi o local com maior percentual de aquisição de peixe (39\% dos consumidores), contra $13 \%$ em peixarias do bairro.

Apesar da tendência do fortalecimento das vendas de pescado nos supermercados, os dados mostram que ainda existe razoável disposição para adquirilos nas feiras livres, o que pode estar relacionado a fatores culturais. Ademais, segundo Kubitza (2002) isso se dá pelo fato do consumidor alegar que na feira livre existe uma maior variedade de peixe e preços menores.

De acordo com Silva (2010), os supermercados com o conceito de vizinhança instalam-se em locais estratégicos para se aproximar mais de seu público-alvo. No município de Belém, nos últimos anos, as grandes redes de supermercados têm 
adotado uma postura de expansão de suas lojas junto aos principais aglomerados urbanos, em concordância com a postura estratégica geral citada anteriormente e, assim, ampliado sua participação no mercado.

Entre os fatores que influenciam a escolha do local de compra, a higiene e o preço tiveram maior percentual de resposta $(33,17 \%)$, seguidos do preço e proximidade do local de venda $(25,13 \%)$.

Quanto à forma de preparo, o peixe frito foi o preferido pelo consumidor, com participação de 93,50\%, seguidos pelo cozido e assado, com $88 \%$ e $72 \%$, respectivamente. O peixe cru representou $30 \%$ de preferência. A preferência de consumo do peixe nas formas frita e cozida deve-se às diversas opções de pratos típicos e receitas regionais como a caldeirada, peixe ao molho, peixe acompanhado de pirão, peixe com açaí, entre outros. Ao contrário, o peixe cru, receita típica dos restaurantes nipônicos, ainda não foi incorporado em larga escala ao hábito do consumidor paraense. Por ser uma culinária exótica é considerada como símbolo de status, seu consumo está associado à camada da população de renda mais elevada.

Os tipos de cortes preferidos foram o filé e a posta, enquanto que o peixe limpo (sem escamas e vísceras) e o inteiro apresentaram menor preferência pelos consumidores, conforme dados da Tabela 3. Isto está associado ao ritmo acelerado das grandes cidades que força a aquisição de produtos prontos, pré-prontos ou que não precisem de muito tempo para o seu preparo, reforçando a tendência de desvalorização dos trabalhos domésticos diários com o preparo da alimentação, estimulando assim novas condutas alimentares, conforme apontado por Silva (2006).

Tabela 3. Tipo de corte preferencial (\%) dos consumidores de peixe no município de Belém, jan. 2014

\begin{tabular}{ccccc}
\hline Preferência & Filé & Posta & Limpo & Inteiro \\
\hline Extremamente & 32,25 & 26,00 & 19,25 & 8,25 \\
Muito & 48,50 & 52,00 & 25,50 & 10,75 \\
Mais ou menos & 12,25 & 10,00 & 21,00 & 13,25 \\
Pouco & 6,00 & 7,50 & 22,50 & 26,25 \\
Nunca & 1,00 & 4,50 & 11,75 & 41,50 \\
\hline
\end{tabular}

Fonte: Dados da pesquisa. 
Dos entrevistados, $86,10 \%$ responderam sempre consumir o peixe na sua própria casa e $11,23 \%$ o consomem em restaurante. Em pesquisa realizada por Kubitza (2002) em cidades das regiões Sudeste, Nordeste e Centro-Oeste do país, $82 \%$ dos consumidores disseram consumir o peixe em casa. O consumo em restaurantes e em buffets foi priorizado por $12 \%$ dos entrevistados.

Com relação à origem do hábito de consumir pescado, foi observado nesta pesquisa que a família (nuclear) foi o principal fator na criação do hábito, com 36,05\% das respostas, seguido por parentes e amigos (21,50\%), meios de comunicação (21,04\%), restaurantes $(16,47 \%)$ e em cursos realizados $(4,94 \%)$. Os meios de comunicação, nos últimos anos, vêm promovendo uma grande divulgação quanto aos benefícios do consumo do peixe para a saúde humana, bem como o marketing, principalmente dos supermercados e restaurantes comunicando suas promoções. Ademais, as ações do governo com a realização de feiras do peixe vivo, semanas do peixe, feiras populares, cartilhas com dicas para manipulação de pescado, além de orientações sobre como verificar a qualidade do produto na hora da compra, tendem a popularizar, ainda mais, o consumo da carne de peixe.

Esses fatores podem estar na base da explicação da expressiva participação dos belenenses no fortalecimento do consumo de peixe e, portanto, na expansão do hábito de consumo. Para quase metade dos entrevistados (49,50\%) o consumo de peixe aumentou ao longo dos últimos dois anos.

\subsection{OBTENÇÃO DO PEIXE}

Durante a compra do peixe, os entrevistados relataram que os fatores mais importantes são o preço $(19,43 \%)$ e o valor nutricional (19,37\%). Entretanto, fatores como tamanho, coloração, embalagem e origem apresentaram valores significativos, revelando que o consumidor belenense avalia um conjunto de fatores para determinar a compra do peixe, conforme demonstrado no Gráfico 2.

Rocha Neto (2010) verificou que no processo de escolha do peixe, 35\% escolhem pelo preço, sendo o mesmo valor encontrado para a qualidade. Silva e Silva (2004) em estudo nos municípios de Macapá e Santana (AP) relataram que o sabor é o atributo que mais influencia a decisão de compra da espécie de peixe, mas $30 \%$ escolheram a espécie, no momento da compra, de acordo com o melhor preço. 


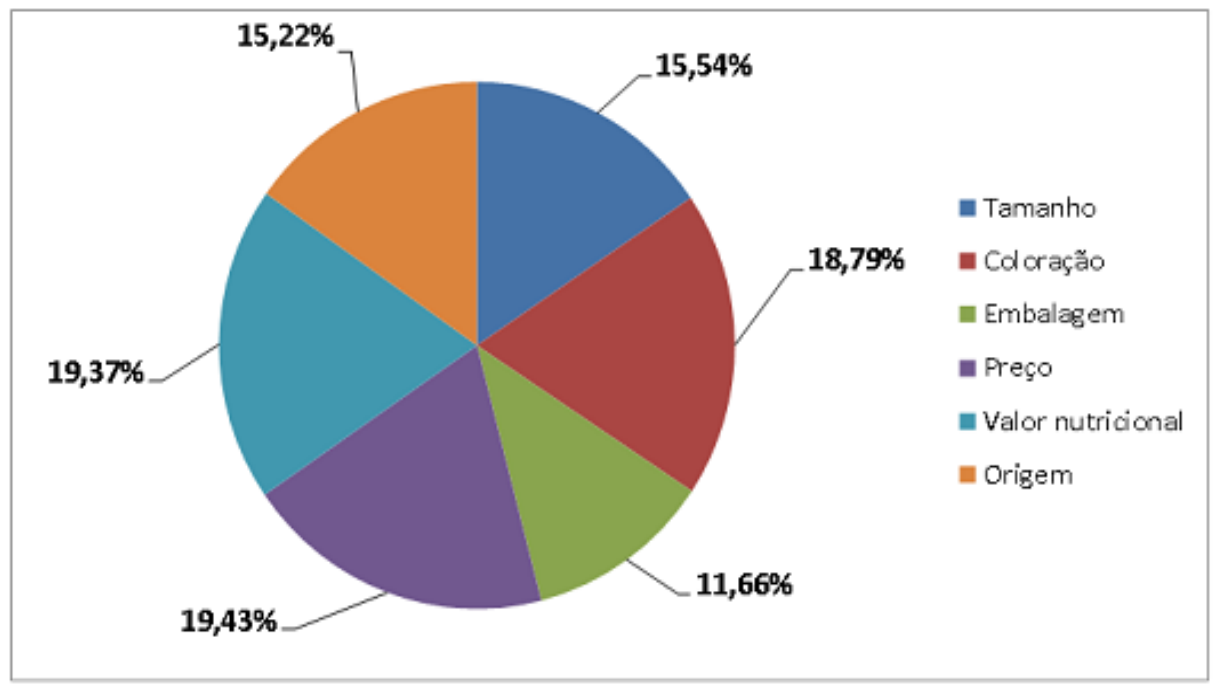

Gráfico 2. Fatores que influenciam a decisão de compra do peixe no município de Belém, jan. 2014

Fonte: Dados da pesquisa.

As dificuldades encontradas pelo consumidor na hora da compra do pescado foram pré-determinadas no formulário, sendo elas: preço, qualidade do peixe e espécie desejada. O Gráfico 3 mostra os resultados encontrados na pesquisa. Os itens apresentaram valores próximos de forma isolada ou em pares, enquanto que a opção "todos" representa um percentual de $57,75 \%$, demonstrando que o consumidor se depara com um conjunto de atributos desfavoráveis no momento da aquisição do peixe.

Kubitza (2002) relatou que o preço do pescado mais alto do que o de outras carnes foi a segunda maior dificuldade encontrada na hora da compra do peixe, conforme destacado por $25 \%$ dos entrevistados. 


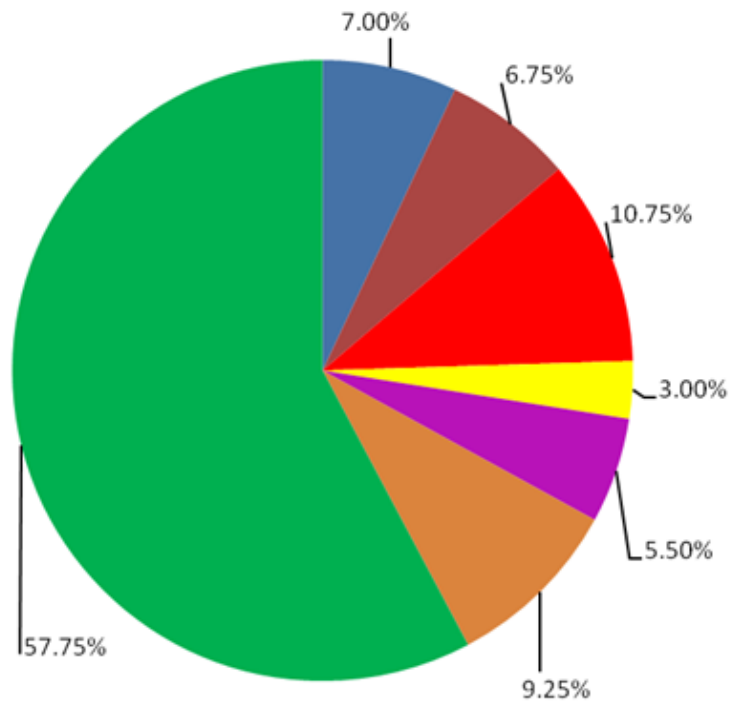

- Bom preço

- Peixe de boa qualidade

Peixe de boa qualidade, bom preço

Peixe de boa qualidade, espécie desejada

- Espécie desejada

Espécie desejada, bom preço

Todos

Gráfico 3. O que é mais difícil encontrar na hora da compra do peixe, segundo os consumidores no município de Belém, jan. 2014

Fonte: Dados da pesquisa.

Com relação aos tipos de peixe, 16,75\% afirmaram preferir peixes de escama enquanto $5,25 \%$ preferem peixes de pele. Um total de $78 \%$ não tem preferência entre os tipos e consomem os dois indistintamente.

Os consumidores apresentaram maior preferência pelo peixe fresco (46,53\%) em relação ao peixe refrigerado (39,37\%) e congelado (14,10\%).

Barbosa et al. (2007), em estudo no município de Belém (PA), encontraram resultados semelhantes para o tipo e o estado de conservação do peixe, confirmando que o consumidor não tem preferência pelo tipo (escama ou pele) e prefere o peixe fresco.

Os consumidores belenenses demonstraram ter uma preferência pelo peixe oriundo da pesca $(77,47 \%)$ em relação aos criados em cativeiro, refletindo nas dez espécies indicadas como as suas preferidas, como evidenciado na Tabela 4, onde apenas uma é proveniente de criatório (tambaqui).

A espécie apontada como preferida foi a dourada (Brachyplatystoma flavicans) que aparece com 78,25\% das indicações espontâneas dos respondentes (Tabela 4). 
Tabela 4. Espécies de peixe mais compradas pelos consumidores no município de Belém, jan. 2014

\begin{tabular}{cccc}
\hline Espécies & Nome científico & Frequência (n) & Percentual (\%) \\
\hline Dourada & Brachyplatystoma flavicans & 313 & 78,25 \\
Pescada Gó & Macrodon ancylodon & 234 & 58,50 \\
Pescada Branca & Plagioscion squamosissimus & 174 & 43,50 \\
Pescada Amarela & Cynoscion acoupa & 170 & 42,50 \\
Filhote & Brachyplatystoma filamentosum & 149 & 37,25 \\
Piramutaba & Brachyplatystoma vaillantii & 75 & 18,75 \\
Tambaqui & Colossoma macropomum & 67 & 16,75 \\
Corvina & Micropogonias furnieri & 62 & 15,50 \\
Mapará & Hypopbthalmus marginatus & 62 & 15,50 \\
Sarda & Pellona flavipinnis & 60 & 15,00 \\
\hline
\end{tabular}

Fonte: Dados da pesquisa.

Nota: cada respondente podia apontar, espontaneamente, as cinco espécies de maior preferência de consumo.

Quando questionados sobre seus conhecimentos quanto ao que seria um produto rastreado, 34,25\% afirmaram saber mais ou menos, 32,50\% afirmaram que pouco sabiam sobre o tema, enquanto $19,75 \%$ afirmaram saber o que era um produto rastreado. Um contingente de $13,50 \%$ informou que não sabiam. Com relação à inspeção do peixe, 53,50\% afirmaram ser importante o peixe conter o selo do Serviço de Inspeção Federal (SIF), que tem por objetivo garantir a qualidade dos produtos e subprodutos de origem animal, desde o processo de abate das diversas espécies animais até a elaboração dos produtos de origem animal comestíveis e os não comestíveis.

No que diz respeito à garantia da procedência do pescado, 55,50\% afirmaram que não estariam dispostos a pagar mais para ter essa informação à sua disposição, 37,75\% que sim e 6,75\% não souberam responder. Tal resultado pode estar relacionado ao fato da maioria dos entrevistados (88\%) considerarem o preço de comercialização do peixe alto, fazendo sua carne ser menos atrativa frente às demais. 
Com relação à verificação do frescor do peixe, $80,25 \%$ responderam que sabiam realizar tal procedimento. Destes, $72,27 \%$ observam cinco itens que atestam a qualidade do pescado (olhos, odor, firmeza do corpo, coloração do corpo e guelras/ brânquias). Quando questionados como aprenderam isto, foram obtidas as respostas observadas no Gráfico 4, onde a família teve papel preponderante (58,62\%).

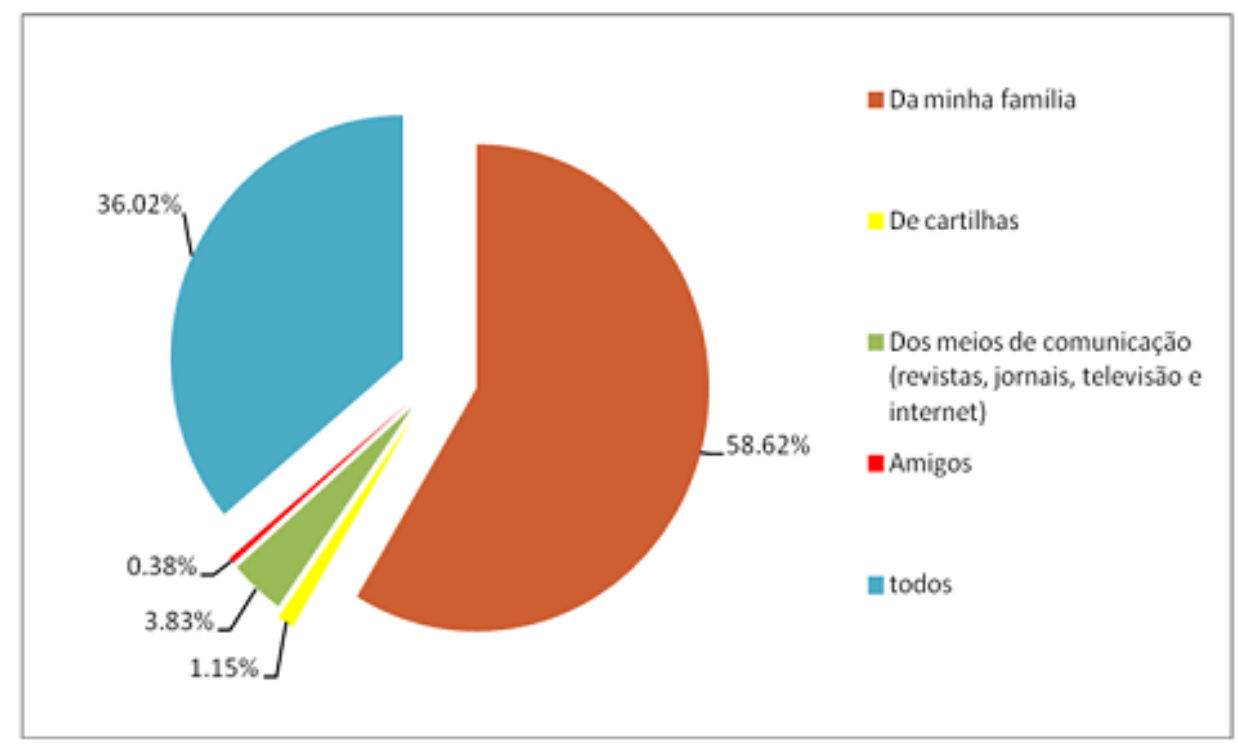

Gráfico 4. Formas de obtenção de conhecimento para atestar a qualidade do peixe pelos consumidores de Belém, jan. 2014

Fonte: Dados da pesquisa.

A percepção dos consumidores quanto à qualidade do peixe comercializado no município de Belém é apresentada na Tabela 5. Conforme se constata, para as opções ótima e boa, a percepção do consumidor é melhor para os produtos comercializados nos supermercados $(77,25 \%)$, seguidos pelos peixes vendidos pelos produtores $(50,00 \%)$, mercado municipal (47,75\%), peixaria do bairro $(44,75 \%)$ e feiras livres $(21,25 \%)$. O produtor/pescador obteve o maior percentual dos que não souberam informar, reflexo do alto percentual dos entrevistados que nunca compram peixe nesse canal de comercialização. Fatores como o alto investimento por parte dos supermercados em infraestrutura e mecanismos de marketing e no caso dos pescadores/produtores pelo fato do peixe posto à venda, normalmente, 
ser fresco ou refrigerado, mantendo suas características naturais, são as razões explicativas para os resultados encontrados.

Tabela 5. Percepção de qualidade do peixe (\%) pelo consumidor no município de Belém, jan. 2014

\begin{tabular}{cccccc}
\hline Percepção & Supermercado & $\begin{array}{c}\text { Peixaria do } \\
\text { Bairro }\end{array}$ & $\begin{array}{c}\text { Mercado } \\
\text { Municipal }\end{array}$ & $\begin{array}{c}\text { Feira } \\
\text { Livre }\end{array}$ & $\begin{array}{c}\text { Produtor/ } \\
\text { Pescador }\end{array}$ \\
\hline Ótima & 22,50 & 11,00 & 9,75 & 6,25 & 25,50 \\
Boa & 54,75 & 33,75 & 38,00 & 15,00 & 24,50 \\
Regular & 15,25 & 17,25 & 26,25 & 35,00 & 5,25 \\
Péssima & 2,25 & 4,00 & 4,25 & 16,25 & 1,00 \\
Não sei & 5,25 & 34,00 & 21,75 & 27,50 & 43,75 \\
\hline
\end{tabular}

Fonte: Dados da pesquisa.

Os consumidores com o ensino médio $(50,81 \%)$ e superior $(64,76 \%)$ de escolaridade, respectivamente, revelaram que ter informações sobre a origem do peixe, a qualidade e a validade serviriam como incentivos para favorecer a compra do produto. Pode-se inferir que os consumidores com um maior nível de escolaridade, por dispor de maior instrução e informações, são mais exigentes quanto à qualidade do produto, tendo em vista garantir a boa saúde.

Fato diferente do encontrado por Barbosa et al. (2007), em estudo no município de Belém (PA), em que apesar de 67,2\% dos consumidores possuírem escolaridade a partir do ensino médio, a maioria não se apresentou preocupada em identificar a qualidade do produto, origem e a inspeção, tal fato foi justificado pela prática cultural que o consumidor tende a assumir que os produtos expostos à venda nos locais tradicionais de compra são de boa qualidade. Alguns consumidores com nível superior revelaram não ter qualquer preocupação com a origem do peixe que consomem, se passam por inspeção ou não, uma vez que ao comprarem nos supermercados, a responsabilidade pela segurança alimentar do produto deve ser uma obrigação do canal de comercialização.

Os dados desta pesquisa, em comparação ao trabalho de Barbosa et al. (2007), revelam uma mudança no perfil do consumidor que atualmente se mostra 
mais exigente com relação à qualidade do produto, contribuindo para o aumento da competitividade e mudança na escolha do canal de compra do pescado.

\section{CONSIDERAÇÕES FINAIS}

O consumidor belenense aprecia bastante a carne de peixe. Seu consumo per capita é da ordem de $21,96 \mathrm{~kg} / \mathrm{hab}$./ano em função de fatores culturais e da abundância do produto na região. Ficou evidenciada uma mudança no perfil do consumidor de peixe do município de Belém que, ao longo dos últimos anos, se tornou mais crítico e exigente com relação à qualidade do produto consumido.

O supermercado foi o local de maior preferência para a aquisição do peixe, demonstrando uma mudança de hábito quanto ao canal de comercialização do produto que tradicionalmente se concentrava nas feiras livres.

A qualidade do peixe vendido nas feiras livres foi a que apresentou maior rejeição, uma vez que $16,25 \%$ dos respondentes a considerou como péssima, comparativamente aos demais canais analisados, fator que pode estar relacionado com a mudança de hábito dos consumidores.

Os consumidores ainda têm grande preferência pelo peixe oriundo da pesca, refletindo nas espécies mais consumidas que são a dourada, pescada gó, pescada branca, pescada amarela, filhote, piramutaba, tambaqui, corvina, mapará e a sarda que, a exceção do tambaqui, são ofertadas a partir da pesca. O preço de venda do peixe no município de Belém é considerado alto pela maioria dos consumidores, sendo ainda o principal fator verificado no momento da compra, seguido pela preocupação com a qualidade do produto.

Comprar o peixe na forma de filé e posta foram os cortes que tiveram maior preferência, pois o ritmo acelerado das grandes cidades estimula a aquisição de produtos de fácil e rápido preparo. Consumir o peixe frito e cozido foram apontados como opções preferenciais de consumo. 


\section{REFERÊNCIAS}

BARBOSA, J. A.; SANTANA, A. C.; SILVA, I. M.; BOTELHO, M. N.; CONDURÚ NETO, J. M. H. Características comportamentais do consumidor de peixe no mercado de Belém. Boletim Técnico Científico do CEPNOR. Belém, v., n. 1, p. 115-133, 2007.

BRASIL. Ministério da Saúde. Secretaria de Atenção à Saúde. Coordenação Geral da Política de Alimentação e Nutrição. Guia alimentar para a população brasileira: promovendo a alimentação saudável. Brasília, 2006.

FAO - ORGANIZAÇÃO DAS NAÇÕES UNIDAS PARAA AGRICULTURA E ALIMENTAÇÃO. The State of World Fisheries and Aquaculture, 2010. Disponível em: <http:// www.fao.org/fishery/sofia/en>. Acesso em: 18 set. 2013.

INSTITUTO BRASILEIRO DE GEOGRAFIA E ESTATÍSTICA IBGE. Belém. Disponível em: < http://www.cidades.ibge.gov.br/xtras/ uf.php?lang $=\& \operatorname{coduf}=15 \&$ search $=$ para $>$. Acesso em: 26 jul. 2015.

INSTITUTO BRASILEIRO DE GEOGRAFIA E ESTATÍSTICA - IBGE. Pesquisa de Orçamento Familiar (POF), 2008-2009. Disponível em: < http://www.sidra.ibge. gov. br>. Acesso em: 18 set. 2013.

KUBITZA, F. Com a palavra os consumidores. Revista Panorama da Aquicultura. Rio de Janeiro, v. 12, n. 69, p. 48-53, 2002.

ROCHA NETO, A. P. Fatores que influenciam na decisão de compra de pescado nas feiras livres de Macapá - AP. 2010. Monografia (Curso de Engenharia de Pesca) - Universidade do Estado do Amapá, 2010.

SIDONIO, L.; CAVALCANTI, I.; CAPANEMA, L.; MORCH, R.; MAGALHÃES, G.; LIMA, J.; BURNS, V.; ALVES JÚNIOR, A. J.; MUNGIOLI, R. Panorama da aquicultura no Brasil: desafios e oportunidades. Rio de Janeiro: BNDES, 2012. (BNDES Setorial 35).

SILVA, C. F. Fatores que influenciam o comportamento de famílias quanto à decisão de compra, preparo e consumo de peixe. 2006. $67 \mathrm{f}$. Dissertação (Mestrado em Agronegócios) - Universidade Federal do Mato Grosso do Sul, Universidade de Brasília, Universidade Federal de Goiás, Campo Grande, 2006. 
SILVA, L. M. A.; SILVA, S. L. F. Fatores de decisão de compra de pescado nas feiras de Macapá e Santana - AP. Boletim Técnico Científico do CEPNOR, Belém, v. 4, n. 1, p. 89-98, 2004.

SILVA, M. R. A. Os supermercados de vizinhança como referência de comércio e consumo e seus impactos na mobilidade urbana. Observatorium: Revista Eletrônica de Geografia, v. 2, n. 4, p. 56-73, 2010.

SILVEIRA, L. S.; ABDALLAH, P. R.; HELLEBRANDT, L.; BARBOSA, M. N.; FEIJÓ, F. T. Análise socioeconômica do perfil dos consumidores de pescado no município de Rio Grande (RS). Sinergia, Rio Grande, v. 16, n. 1, p. 9-19, 2012.

VENTURA, R. Mudanças no perfil do consumo no Brasil: principais tendências nos próximos 20 Anos. Rio de Janeiro: Macroplan - Prospectiva, Estratégia \& Gestão, 2010.

Recebido em: 03 de agosto de 2015 Revisado em: 22 de dezembro de 2015 Aceito em: 21 de janeiro de 2016 